\title{
Professor Pierre Budin (1846-1907) of Paris, and modern perinatal care
}

\author{
Peter M Dunn
}

Pierre Constant Budin was born in Enancourtle-Sec near Beauvais in 1846. His parents were farmers. After schooling at the College of Beauvais and at the Lycée Napoleon where he obtained a baccalaureate in philosophy, he studied medicine for four years in Paris. There he came under the influence of the great $\mathrm{Dr}$ Tarnier, and on qualifying in 1871 , became his house officer at the Hôpital de la Charité, and later his collaborator there, and also both at the Maternite and the Tarnier Clinique. When Tarnier died in 1897 he named Budin as the man to carry on his great work. The following year, Budin was made Professor of Obstetrics at the University of Paris, director of the Tarnier Clinique, and a member of the Academy of Medicine.

Budin was an outstanding doctor, scientist, and teacher. To quote from his obituary address by the President of the Academy, ${ }^{1}$ he thought only of science, of doing good, and of friendship. He united intelligence with humanity and vision. In obstetrics he excelled as a clinician rather than as a surgeon. Although frail, he had a great capacity for work and a tenacious determination that assured the success of his projects. He was a good judge of people and also good at getting them to work for him. Always courteous and loyal he demanded the same severe discipline of his collaborators as he set for himself. Budin was also a cultured man finding pleasure and relaxation in literature and the arts. He had many friends and was loved by his students. His teaching was marvellously clear and his lectures were delivered with authority and charm. ${ }^{2}$ With a high reputation throughout Europe and North America, he received many honours including the distinction of being made an Officer of the Légion d'honneur.

Budin's contributions to perinatal medicine were many. As a house officer his publications in 1875 on the treatment of birth asphyxia and the management of the umbilical cord attracted wide attention.

Department of Perinatal Medicine and Child Health, University of Bristol, Southmead Hospital, Bristol BS10 5NB P M Dunn

Correspondence to: Professor P M Dunn.

\section{On the management of the umbilical cord:}

'During my time at the Maternité in Paris, my chief, M Tarnier, in one of his visits to the labour ward in 1875, recommended me not to tie and not to cut the umbilical cord as soon as the child was born. When

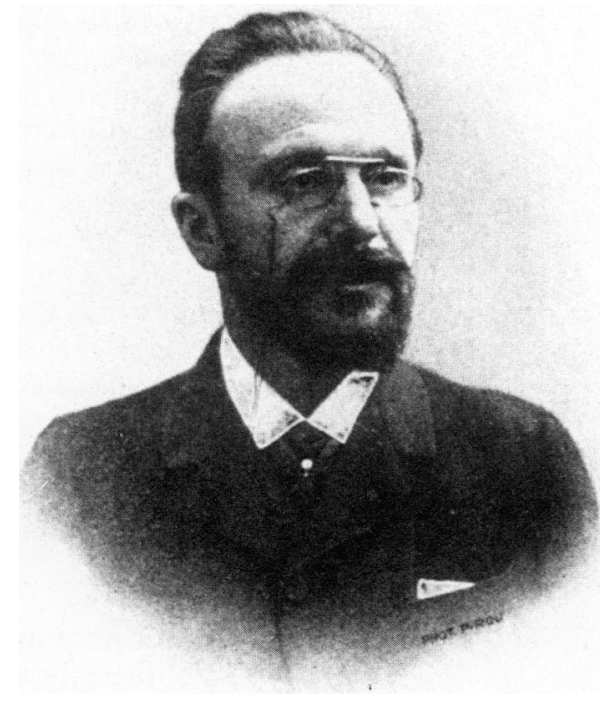

Professor Pierre Budin, 1846-1907.

one hurries too much in performing this operation between two previous ligations, one finds, he said, the placenta full of blood and one risks, on the one hand, depriving the child of a certain quantity of blood which, with more patients, would have returned to its circulatory system. On the other hand, one runs the risk of encountering in the extraction of the afterbirth some difficulties produced by the turgescence of the umbilical vessels and the consequent increase of the placental mass'.

In 1876 Budin presented his doctorate thesis on cephalo-pelvic anatomic relations, a subject that he later applied to studies on disproportion. He wrote treatises on giving birth and on breast feeding, but the work for which he is best remembered is Le Nourrisson, written as 10 lectures for medical students and first published in Paris in 1900. Fortunately this text was translated into English in 1907 by an Edinburgh doctor, William Maloney. ${ }^{3}$ Budin was greatly concerned at the very high infant mortality in France. He appreciated the need to educate mothers, as well as colleagues, in infant care from birth until weaning, and also the need to provide ongoing supervision through the creation of follow up clinics. He established his first baby clinic in Paris in 1892. 
There infants were seen each week, examined, and weighed and instruction given to their mothers on their hygiene and care. Particular attention was given to keeping them warm, clean, and to providing them with 'safe' milk. Careful audit revealed a remarkable fall in mortality and similar clinics were set up in the provinces and also in England. The following extracts from The Nursling reveal the clarity with which he grasped the essentials of neonatal care.

On the responsibilities of the accoucheur: 'Nowadays, thanks to antisepsis, death has practically been banished from our maternity hospitals and morbidity reduced almost to its minimum. Further, through the perfection of instruments and the advancement of operative technique, obstetrical interference has become much simpler and safer, so that the accoucheur, freed from anxiety as to the fate of the mother, can now devote his attention to the needs of the infant. Before parturition, he supervises the hygiene of the expectant mother so that she may arrive at term in a healthy condition; during delivery, he takes every precaution to ensure that the child will be born sound and viable; and throughout the first two years of life, he directs its feeding with the utmost care....'

\section{On gestational age and weight at birth:}

'To appreciate the vitality of infants born before term, it is necessary, not only to take into account their weight, but also the length of time they have remained in the uterine cavity ... Everything ought to be done to ensure that an infant be born at term, well-developed, and in a healthy condition. But in spite of every care, infants are born prematurely ... In addition there are tiny, puny infants with great vitality. Their movements are untiring and their crying lusty, for their organs are quite capable of performing their allotted functions. These infants will live, for although their weight is inferior ... their sojourn in the womb was longer'.

\section{On the use of incubators:}

'The idea occurred to Tarnier to utilise an apparatus similar to that which is used to obtain artificially the hatching of hens' eggs. In 1880 , by the way of a trial, his first incubator was installed at the Maternité ... To the one which had been placed on my wards at the Charité, I adapted, in 1883, a Regnard regulator. A uniform temperature could thus be ensured, for if it rose a little too high a warning was immediately given by an electric bell ... a large reservoir has been substituted for the water bottles. Lastly, these incubators ... are made nowadays of glass and wood, which is relatively cheap, and allows them to be more easily moved from place to place ...
Ought weaklings in incubators to be clothed or not? One of my colleagues, having observed that by their movements they tend to rid themselves of their coverings, now leaves them quite naked. But if, perchance, the renewal of the hot water at the proper time be neglected, the infant would become very quickly chilled. It is preferable while not restricting their movements by swaddling, at least to clothe them lightly, so as to conserve their warmth and yet leave them absolute freedom ...

It is better by far to put the little one in an incubator by its mother's bedside. The supervision which she exercises is not to be lightly estimated. We have not always a staff so zealous as the present; and, if the nurse be negligent, the mother does not fail to remark that the incubator is being allowed to grow cold. Further, it is possible, as you will see, so to arrange that the mother feeds the infant herself, and thus on leaving the hospital not only will the weakling have been saved, but a suckling mother will also have been conserved to it'.

\section{On hypothermia and cyanotic attacks:}

'At the moment of birth, the infant at term experiences a slight fall of temperature ... From $38^{\circ} \mathrm{C}$ to $37^{\circ} \mathrm{C}$, to $36^{\circ} \mathrm{C}$, and sometimes even lower ... When weaklings are brought from other hospitals, the city, or the surrounding districts, to the wards set apart for them at the Maternité, they generally arrive, especially in winter, very chilled. If they must be taken from one place to another, they should be carefully wrapped up, and one or two hot water bottles should be placed beside them. They become chilled with astonishing rapidity ... Several years ago, in passing one morning through the wards, I saw a premature infant which showed signs of sclerema. I touched it; it was cold. I wished to take its temperature, but the mercury would not leave the bulb, to register the lowest point on the scale, $28^{\circ} \mathrm{C}$. Having sent for another, I found the temperature was $25^{\circ} \mathrm{C}$... The mortality among prematurely born infants when their temperature is allowed to become too much depressed is really appalling, and too great precautions cannot be taken to protect them.

The temperature of weaklings must be maintained at normal. Thanks to the use of incubators, hot baths, and other means, this may be done; but it is not the only essential. A living being must generate heat, the infant must produce its own animal heat, and we must provide it with fuel by giving it food ... I observed that a few days after their admission infants frequently had attacks of cyanosis ... I noticed that, as a rule, infants, in whom they occurred, were underfed ... The first thing to do is put them in a glass incubator ... When an attack takes place the weakling 
must be lifted out of its incubator, and everything tried to bring about the reestablishment of the respiration ... I have had recourse with success to insufflation in a few cases ... Afterwards, it is necessary to supervise the feeding with a view to increasing the amount absorbed. If the child does not wish to take the breast, or is not strong enough to suck, it must be fed from a spoon, and if it cannot swallow, gavage must be employed'.

\section{On the wet nurses and hygiene:}

'Congenital feebleness greatly diminishes an infant's power of resistance ... We prohibited the infants of the wet-nurses from being taken into the dressing-room for the weaklings. We obliged every wet-nurse to wash her face and hands, and change her uniform each time she went to feed the weaklings ... There is a (separate) apartment to serve as a dressing-room and lavatory for the wet nurses ...'

\section{On mother-child bonding and breast feeding:}

'I have pointed out to you that an infant treated at the department for weaklings is separated from its mother. To save their lives is our primary concern, but afterwards, their mothers, no longer able to furnish the milk necessary to their nutrition, confide them to paid breast wetnurses. I have been grieved to see a certain number of women come more and more rarely to visit their child, and gradually lose all interest in it. At length, when they are notified that it was about to be discharged, they made no response, and the infant, thus abandoned, I had to hand over to "Les Enfants Assistes ... This is the reason, gentlemen, why you have seen me insist so strongly in this Clinique on two points: first, save the infant, the essential point; second, save it in such a way that when it leaves the hospital it does so with a mother able to suckle it. So when a weakling has to be fed for a time by a wet-nurse I place a vigorous infant at the mother's breast. Her lacteal secretion is thus established. Soon she can nurse her own little one, and, on leaving the Clinique, will continue to suckle it'.

\section{On the sterilisation of milk:}

'Pasteur and his pupils have demonstrated the dangers of milk as a carrier of infection. Bacteria develop in it with extreme facility ... Diarrhoeas, including infantile cholera, the death-scourge of infants during summer, are caused by microbes ...
Cold does not destroy either pathogenic or non-pathogenic organisms. Heat is the bactericidal agent generally used for milk, and it is applied chiefly by the methods of pasteurisation and sterilisation. In pasteurisation the liquid is heated once to about $60^{\circ} \mathrm{C}$, and then rapidly cooled. This method enables the milk to be sent long distances; it retards the multiplication of germs, but does not kill them: as milk thus treated is not sterile, neither is it harmless ... Sterilisation of milk may be achieved in various ways: the milk may be boiled; heated in closed vessels to $100^{\circ} \mathrm{C}$, for forty-five minutes; raised to $110^{\circ} \mathrm{C}$, for a sufficient length of time; or subjected to discontinuous heating ... Any milk remaining in a bottle after a feed ought not to be again offered to the infant, for it is no longer sterile. The organisms of the mouth, entering the bottle through the teat, rapidly multiply, and produce alterations in the milk'.

On the prognosis of premature infants: 'It has been alleged that they remain puny and weakly all their lives, that many of them have Little's disease, and that they have a feeble intellectual development. That is not so. During my three years at the Maternité, out of 1100 admissions I saw only one case of Little's disease, and it was consequent on a difficult intervention in a pelvic presentation, and not due to debility ... As for intelligence, there is a little friend of mine who three days after birth weighed only 950 grams. She is seven years old and speaks French and German. I think that the allegations regarding the permanent bodily and mental debility of weaklings ... are entirely without foundation'.

While on a visit to Marseilles in 1907 in order to set up a baby clinic, he contracted influenza and pneumonia and died there after a short illness. He was 60 years old. So passed away one who may be described with justice as the father of modern perinatal care.

Budin had married Marie-Thérèse Sasles, a young teacher of English in 1893 but, sadly, there were no children. After his death his wife continued his work and in 1923 was herself accorded the Légion d'honneur. At the presentation she said: 'Everything I did, I did by love of my husband; then by love of infants and their mothers who are frequently admirable'.

1 Décès de MP Budin. Bulletin de l'Académie de Médicine 1907; 57: $163-6$.

2 Toubas PL. Pierre Budin, creator of perinatal medicine. Am Acad Pediatr Newsletter 1992; 17: 1-3.

3 Budin P. The nursling. The feeding and hygiene of premature and full-term infants. Translated by WJ Maloney. London: Caxton, 1907. 